\title{
PAPERS
}

\section{Neuromuscular function of the human lower oesophageal sphincter in reflux disease and Barrett's oesophagus}

\author{
S D Smid, L A Blackshaw
}

\begin{abstract}
Background-Columnar lined (Barrett's) oesophagus is often considered a sequel to chronic severe reflux disease. Aberrant lower oesophageal sphincter (LOS) motility associated with Barrett's oesophagus includes reduced basal LOS pressures. The aim of this study was to characterise neuromuscular function of the LOS in normal (squamous cell carcinoma (SCC) with uninvolved LOS) and reflux affected (Barrett's) oesophagus in vitro.

Methods-Strips of LOS muscle were prepared at biopsy following oesophagectomy from 16 patients with SCC and seven patients with oesophageal adenocarcinoma and Barrett's oesophagus associated with a history of reflux disease. LOS smooth muscle responses were recorded in response to electrical field stimulation (EFS), potassium chloride (KCl), DMPP, isoprenaline, capsaicin, bethanechol, and tachykinins.
\end{abstract}

Results-Basal LOS tone and LOS relaxations in response to isoprenaline, EFS, and DMPP were not significantly altered in the Barrett's group. After tetrodotoxin pretreatment, responses to $\mathrm{KCl}$ and DMPP were significantly reduced in the SCC but not in Barrett's LOS. Maximal contraction in response to bethanechol was significantly decreased in Barrett's LOS while substance $P$ and NK-2 receptor mediated contraction was unaltered. Capsaicin, NK-1, and NK-3 receptor agonists exerted negligible effects on LOS tone.

Conclusions-LOS muscle strips from patients with reflux associated Barrett's oesophagus exhibit a reduction in cholinergic muscle contraction while retaining similar features of basal tone, responses to tachykinins, and inhibitory muscle and neural function. Enteric inhibitory neurones in LOS muscle strips from patients with reflux associated Barrett's oesophagus display resistance to axonal sodium channel blockade. No evidence for functional NK-1 or NK-3 receptors or capsaicin sensitive axon collateral reflexes was observed in the human LOS.

(Gut 2000;46:756-761)
Keywords: Barrett's oesophagus; lower oesophageal sphincter; tachykinins; inhibitory motorneurones; tetrodotoxin; smooth muscle

Columnar lined (Barrett's) oesophagus is often considered a sequel to chronic severe gastrooesophageal reflux disease, with prevalence rates of $1-10 \%$ in patients presenting for endoscopy with symptoms of gastrooesophageal reflux disease. ${ }^{1}$ Barrett's oesophagus is also associated with an increased risk of the development of oesophageal cancer. ${ }^{1}$ Aberrant upper gastrointestinal motility associated with Barrett's oesophagus includes reduced basal lower oesophageal sphincter (LOS) pressure, decreased distal oesophageal contraction amplitude, impaired oesophageal clearance, delayed gastric emptying, and increased frequency of transient LOS relaxations, ${ }^{2-5}$ factors which often predominate in gastrooesophageal reflux disease. In addition, there are reports of decreased perception of oesophageal acid $^{3}$ and balloon distension ${ }^{6}$ in Barrett's oesophagus. These findings indicate a broad pattern of alterations in both upper gastrointestinal sensation and motility associated with Barrett's oesophagus. The mechanisms underlying increased frequency of transient LOS relaxations and LOS hypotonia in Barrett's oesophagus are unknown. Animal surgical models of acute reflux disease, while successful in generating a columnar lined oesophagus, ${ }^{78}$ have yet to assess motility changes to the LOS. While animal models of acute oesophagitis have shown functional deficits in LOS function in vitro, ${ }^{9} 10$ these are inappropriate models to compare with LOS function of the chronic or severely reflux affected (and columnar lined) oesophagus.

In the present study we have compared LOS smooth muscle and non-adrenergic noncholinergic (NANC) neural function in LOS biopsies from patients with severe or chronic gastro-oesophageal reflux disease concomitant

Abbreviations used in this paper: SCC, squamous cell carcinoma; LOS, lower oesophageal sphincter; NANC, non-adrenergic non-cholinergic; EFS, electrical field stimulation; DMPP,

1,1-dimethyl-4-phenylpiperazinium iodide; TTX, tetrodotoxin. 
with Barrett's oesophagus, with LOS biopsies from patients with normal squamous epithelium at the gastro-oesophageal junction and no pre-existing oesophagitis or history of reflux disease, to characterise the potential abnormalities in peripheral neuromuscular function of the severely reflux affected columnar lined LOS.

\section{Methods}

MUSCLE STRIP PREPARATION

Experiments were performed in tissues from a total of 23 patients referred to the Professorial and Oesophago-gastric Unit of the Royal Adelaide Hospital. All studies were performed in accordance with the guidelines of the human ethics committee of the Royal Adelaide Hospital, Adelaide. Strips of LOS were prepared at biopsy following gastro-oesophagectomy from a maximum of 16 patients with squamous cell carcinoma (SCC; mean age 67 (3) years) and seven patients with Barrett's oesophagus (suspected adenocarcinoma indication for surgery; mean age 61 (3) years). Only Barrett's patients with a discernable history of reflux disease were used. Columnar lined mucosa of the distal oesophagus was confirmed at pathology. Immediately following resection and removal of the cardia and oesophagus, sections (approximately $1 \times 1 \mathrm{~cm}$ ) of tissue were removed from the gastro-oesophageal junction $(0.5-1.0 \mathrm{~cm}$ above the angle of His, corresponding to sling fibres) ${ }^{11}$ and placed in ice cold Krebs solution bubbled with carbogen $\left(95 \% \mathrm{O}_{2}, 5 \% \mathrm{CO}_{2}\right)$. Manometric and anatomical evidence suggests that muscle from this region correlates with the functional lower oesophageal sphincter. ${ }^{12}{ }^{13}$ In all cases only biopsy specimens of the gastrooesophageal junction that were free of malignancy were used; this was confirmed by tissue pathology at the section margins.

After removal of mucosa, submucosa, and longitudinal muscle, tissue was divided under sharp dissection to give four bands of circular muscle and attached myenteric plexus of dimensions $2 \mathrm{~mm}$ wide, $5 \mathrm{~mm}$ long. These were placed in individual $10 \mathrm{ml}$ water jacketed organ baths containing carbogenated Krebs solution at $37^{\circ} \mathrm{C}$ of the following composition $(\mathrm{mM}): \mathrm{NaCl} 118, \mathrm{NaHCO}_{3} 25, \mathrm{KCl} 4.6$, $\mathrm{MgSO}_{4} 1.2, \mathrm{NaH}_{2} \mathrm{PO}_{4} 1.3$, glucose $11, \mathrm{CaCl}_{2}$ 2.5. One end of the tissue was fastened to a support while the other was attached to an isometric force transducer (FTO3, Grass, Quincy, Massachusetts, USA). On either side of the tissue support a pair of platinum electrodes was used for electrical field stimulation (EFS). Each strip was placed under an initial tension of $20 \mathrm{mN}$ and left to equilibrate for 90 minutes. This corresponded to a degree of tissue stretch of approximately $200 \%$ of the initial resting length of the muscle strip, which has been shown to be within the optimal range for mechanical performance of the isolated human LOS. ${ }^{14}$ Only muscle strips from the gastrooesophageal junction developed a stable spontaneous tension at rest and exhibited a typical relaxation profile in response to EFS. These criteria were considered to verify that the origin of the muscle strips was from the LOS. ${ }^{15}{ }^{16}$
PHYSIOLOGICAL AND PHARMACOLOGICAL STUDIES EFS was delivered via rectangular wave pulses from a stimulator (S48, Grass Instruments, Quincy, Massachusetts, USA) with three minute intervals between each stimulus. Responses of LOS muscle strips to EFS (1-20 $\mathrm{Hz}, 50 \mathrm{~V}, 1 \mathrm{~ms}$ for 5 seconds), $\mathrm{KCl}$ (neural depolarization; $20 \mathrm{mM}$ ), 1,1-dimethyl-4phenylpiperazinium iodide (DMPP; nicotinic agonist; $\left.10^{-5} \mathrm{M}\right)$, isoprenaline $\left(10^{-5} \mathrm{M}\right)$, capsaicin $\left(10^{-6} \mathrm{M}\right)$, in addition to cumulative increasing concentrations of bethanechol $\left(10^{-10}-10^{-5} \mathrm{M}\right)$, substance $\mathrm{P}$, [Sar, Met $\left(\mathrm{O}_{2}\right)^{11}$ ]substance $\mathrm{P}$ (NK-1 receptor selective agonist), $\left[\beta-\mathrm{Ala}^{8}\right]$-neurokinin A 4-10 (NK-2 receptor selective agonist), and [Succinyl-Asp ${ }^{6}$, MePhe ${ }^{8}$-substance P 6-11 (senktide; NK-3 receptor selective agonist; all $10^{-10}-10^{-6} \mathrm{M}$ ) were measured and recorded onto hard disk using Labview based software (MAD, Charles Malbert). All experiments were performed in the presence of atropine $\left(10^{-6} \mathrm{M}\right)$ and guanethidine $\left(3 \times 10^{-6} \mathrm{M}\right)$, except where bethanechol was used to stimulate muscle contraction.

DATA ANALYSIS

Relaxation responses of the LOS were measured relative to the response of a supramaximal concentration of isoprenaline $\left(10^{-5} \mathrm{M}\right)$ or to baseline tension, while contractions were measured as a percentage of the maximal response to $\left[\beta-\mathrm{Ala}^{8}\right]$-neurokinin $A$ 4-10 $\left(10^{-6} \mathrm{M}\right)$ or as absolute contraction. Data are expressed as mean (SEM) of $n$ subjects. Non-linear regression of concentrationresponse data, $\mathrm{E}_{\mathrm{MAX}}$ and $\mathrm{EC}_{50}$ calculations were performed using Prism 2.0b (Graphpad, San Diego, California, USA). Statistical analysis was performed using a paired Student's $t$ test for pretreatment studies using tetrodotoxin, an unpaired $t$ test for comparison of individual $\mathrm{E}_{\mathrm{MAX}}$ and $\mathrm{EC}_{50}$ values between groups, or one way ANOVA for group point comparisons (where $\mathrm{E}_{\mathrm{MAX}}$ and $\mathrm{EC}_{50}$ values were not appropriate), with group means in this instance compared using Bonferroni's post hoc test. A p value $<0.05$ was considered significant.

DRUGS

Substance P, [Sar ${ }^{9}$, Met $\left(\mathrm{O}_{2}\right)^{11}$ ]-substance P, and senktide were obtained from Auspep (Melbourne, Australia). [ $\left.\beta-\mathrm{Ala}^{8}\right]$-neurokinin A 4-10, atropine sulphate, 1,1-dimethyl-4phenylpiperazinium iodide (DMPP), isoprenaline hydrochloride, bethanechol chloride, capsaicin, tetrodotoxin, and guanethidine sulphate were obtained from Sigma-Aldrich (Sydney, Australia). All drugs were dissolved in saline, except for capsaicin which was dissolved in saline, ethanol, and Tween $80(8: 1: 1 \mathrm{v} / \mathrm{v} / \mathrm{v})$.

\section{Results}

LOS TONE AND MUSCLE RELAXATION

After placing LOS muscle strips under $20 \mathrm{mN}$ of basal tension they developed additional tone during the equilibration period. Basal tension was reduced in the Barrett's group (40 (6) $\mathrm{mN}$ $v 45$ (3) $\mathrm{mN}$ in the SCC group) but this was not significant. 

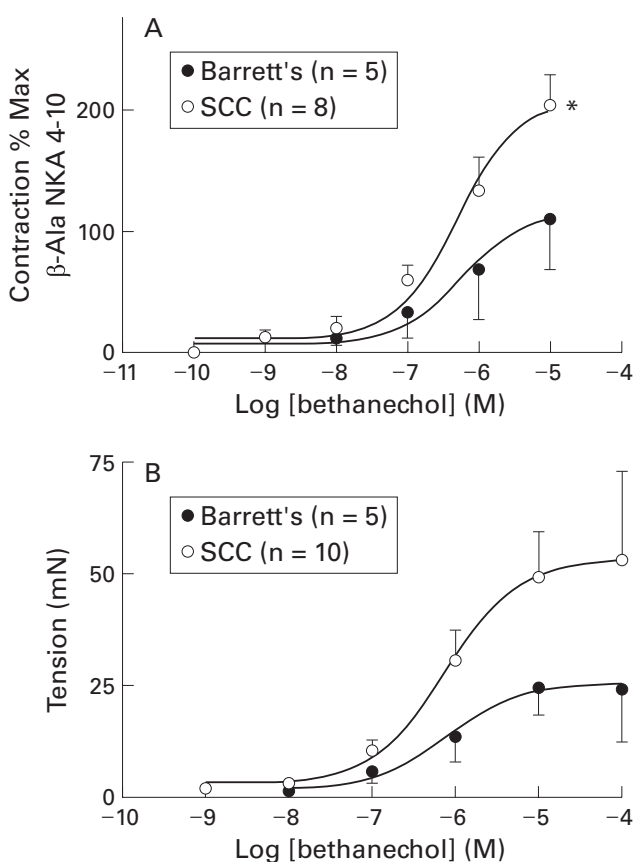

Figure 1 Concentration-response curve representing contraction in response to bethanechol in squamous cell carcinoma (SCC) and Barrett's lower oesophageal sphincter (LOS) muscle strips, expressed in terms of absolute contraction (B) or relative to maximal contraction in response to the NK-2 receptor agonist

$\left[\beta-A l a^{8}\right]$-neurokinin A 4-10 (A). Contraction was suppressed based on both indices and significantly decreased in the Barrett's group (significant difference in maximal responsiveness: $E_{M A X} 264.1$ (24)\% SCC v 145 (50)\% Barrett's, $\left.{ }^{\star} p<0.05\right)$.

LOS muscle relaxation in response to isoprenaline $(10 \mu \mathrm{M})$ consisted of a prolonged relaxation relative to basal tension (59.7 (4)\% Barrett's, 44.8 (4)\% SCC). While the Barrett's group exhibited greater relaxation following isoprenaline, there were no significant differences in the evoked relaxation between groups when measured relative to basal tension.

LOS CHOLINERGIC, TACHYKININERGIC, AND CAPSAICIN INDUCED RESPONSES

Bethanechol administration elicited dose dependent contraction that was maximal at $10^{-4} \mathrm{M}$. In the Barrett's group there was a reduction in maximal absolute tension development (fig 1B) and a significant reduction in

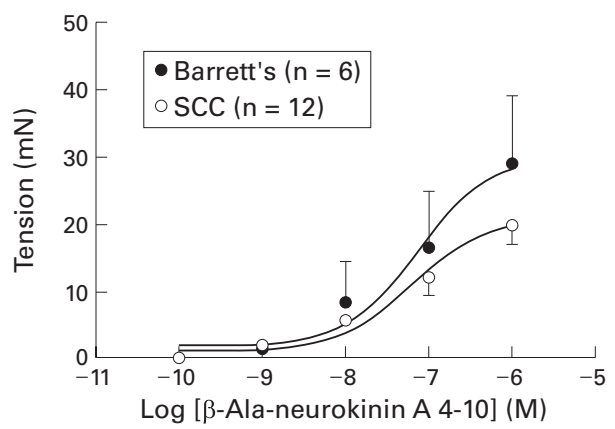

Figure 2 Concentration-response curve representing absolute contraction in response to the NK-2 receptor agonist $\left[\beta-\right.$ Ala $\left.{ }^{8}\right]$-neurokinin A 4-10 in squamous cell carcinoma (SCC) and Barrett's lower oesophageal sphincter (LOS) muscle strips. While increased, maximal responsiveness was not significantly altered in Barrett's group. maximal responsiveness when measured relative to the maximum contraction following selective NK-2 receptor activation with [ $\beta$-Ala ${ }^{8}$ ]-neurokinin A 4-10 ( $\mathrm{E}_{\mathrm{Max}}$ Barrett's 145 (50) $\%$, SCC $264(24) \%$; $<<0.05)$ (fig $1 \mathrm{~A})$.

$\left[\beta-\mathrm{Ala}^{8}\right]$-Neurokinin A 4-10 administration caused contraction of the human LOS that was dose dependent from $10^{-9}$ to $10^{-6} \mathrm{M}$ and near maximal at $10^{-6} \mathrm{M}$ (fig 2 ). [ $\left[3-\mathrm{Ala}^{8}\right]-N e u r o k i n i n$ A 4-10 displayed similar dose-response curves in LOS muscle strips from the SCC and Barrett's groups. There were no significant differences in maximal responsiveness when measured in terms of changes in absolute tension.

Substance $\mathrm{P}$ mediated contractions were small in comparison $(30 \%$ of maximal $\left[\beta-\mathrm{Ala}^{8}\right]$-neurokinin A 4-10 evoked contraction) and were not significantly altered in muscle strips from the Barrett's group (fig 3). [Sar', Met $\left(\mathrm{O}_{2}\right)^{11}$-Substance $\mathrm{P}$ and senktide elicited negligible effects on LOS tone in vitro and these were not significantly different in the Barrett's group. Capsaicin $\left(10^{-6} \mathrm{M}\right)$ failed to elicit a response in LOS muscle strips from either SCC or Barrett's LOS, as did its vehicle (see Drugs).

LOS RESPONSES TO ELECTRICAL FIELD STIMULATION (EFS) AND NANC NEURAL ACTIVATION

LOS muscle strips responded to EFS (1-20 $\mathrm{Hz}, 50 \mathrm{~V}, 1 \mathrm{~ms}$ duration for 5 seconds) with a predominant frequency dependent relaxation that was near maximal at $10 \mathrm{~Hz}$ (fig 4). While responses to EFS were attenuated in Barrett's LOS, they were not significantly different (fig 4). Tetrodotoxin significantly inhibited the relaxation in response to EFS at $5 \mathrm{~Hz}$ in both Barrett's (-55.1 (9)\% control $v-4.7$ (2)\% with TTX; $\mathrm{p}<0.05)$ and SCC $(-62.6(13) \%$ control $v-3.33(0.7) \%$ with TTX; $\mathrm{p}<0.001)$ groups relative to maximal relaxation to isoprenaline.

DMPP and $\mathrm{KCl}$ administration evoked rapid and powerful relaxations of the human LOS, which were greater than the relaxation elicited by supramaximal concentrations of isoprenaline. However, there were no differences in degree of relaxation between the SCC and Barrett's groups following either DMPP or

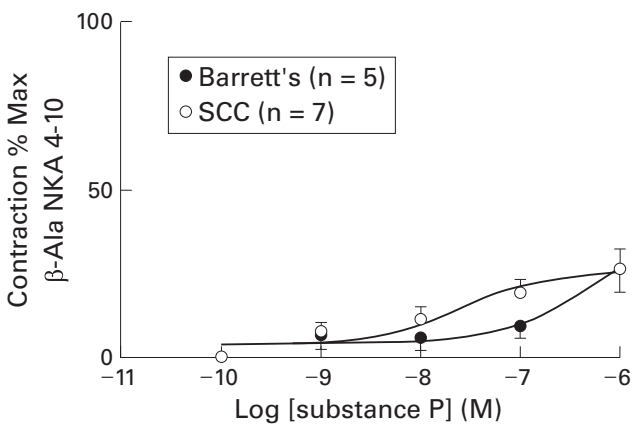

Figure 3 Concentration-response curves showing the response to the non-specific neurokinin receptor agonist substance $P$ in squamous cell carcinoma (SCC) and Barrett's lower oesophageal sphincter (LOS) muscle strips. Substance P elicited modest contraction in LOS muscle strips of approximately $30 \%$ of the maximal contraction to the $N K-2$ receptor agonist $\left[\beta-A l a^{8}\right]$-neurokinin $A$ 4-10. There was no difference in tension development in the Barrett's or SCC group in response to substance P. 


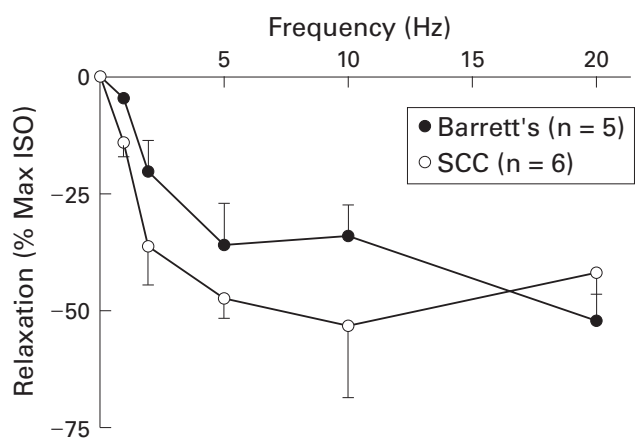

Figure 4 Frequency-response curve representing relaxation in response to electrical field stimulation in squamous cell carcinoma (SCC) and Barrett's lower oesophageal sphincter (LOS) muscle strips. While attenuated at most frequencies, relaxation was not significantly altered in the Barrett's group. Relaxation expressed relative to relaxation induced by a supramaximal concentration of isoprenaline (ISO; $10 \mu \mathrm{M})$.
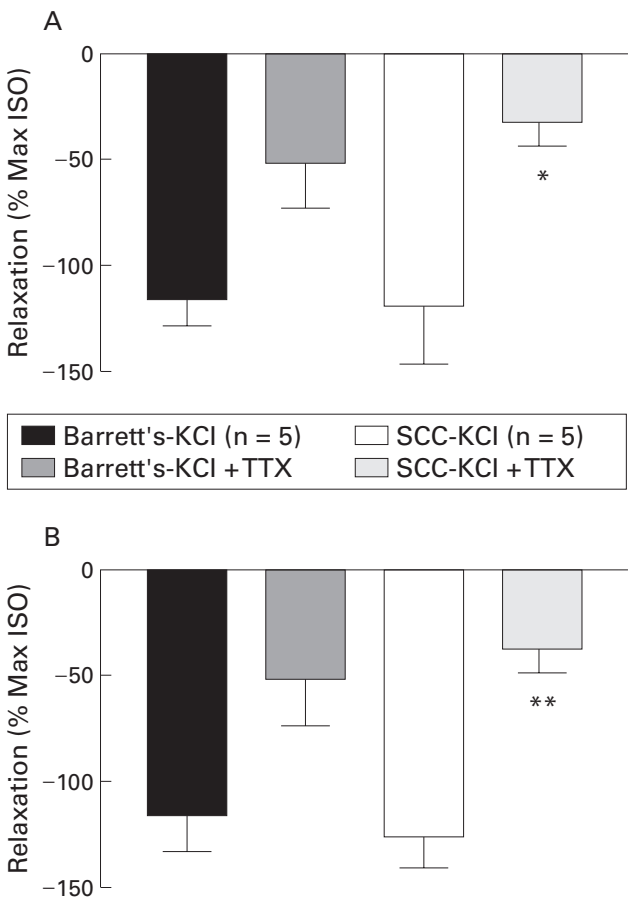

Barrett's-DMPP ( $n=5) \quad \square$ SCC-DMPP ( $n=6)$ Barrett's-DMPP + TTX $\square$ SCC-DMPP + TTX

Figure 5 Histogram representing lower oesophageal sphincter (LOS) muscle strip relaxation to KCl $20 \mathrm{mM}$ $(A)$ and DMPP $10 \mu M(B)$ in the control and Barrett's group, before and after axonal sodium channel blockade with tetrodotoxin (TTX $1 \mu \mathrm{M})$. Relaxation expressed relative to relaxation induced by a supramaximal concentration of isoprenaline $(10 \mu \mathrm{M})$. Muscle strips from Barrett's LOS showed similar degrees of relaxation to either DMPP or KCl compared with controls. Tetrodotoxin significantly inhibited relaxation to DMPP in both groups $\left({ }^{\star} p<0.001\right.$ controls, ${ }^{\star} p<0.05$ Barrett's) and inhibited relaxation to $\mathrm{KCl}$ in the control $\left({ }^{\star} p<0.05\right)$ but not in the Barrett's group.

$\mathrm{KCl}$ administration (fig 5A, B). Following pretreatment with tetrodotoxin, $\mathrm{KCl}$ and DMPP induced relaxations were significantly inhibited in SCC ( $\mathrm{KCl}, \mathrm{p}<0.05$ (fig 5A) and DMPP, $\mathrm{p}<0.001$ (fig $5 \mathrm{~B}$ )) but not in Barrett's LOS.

\section{Discussion}

In the present study we have investigated the effects of severe gastro-oesophageal reflux dis- ease complicated by Barrett's oesophagus on the functional activity of the lower oesophageal sphincter (LOS) in vitro, including measurements of smooth muscle and inhibitory motorneuronal activity. While there are many clinical studies showing a range of motility changes in the upper gastrointestinal tract in reflux associated Barrett's oesophagus, ${ }^{2}$ none has addressed potential alterations in peripheral neuromuscular function in the LOS. The range of pharmacological markers used in this study reflects characterisation of a range of neurotransmitter functions in the human LOS. Generally there were few differences between SCC and Barrett's LOS with respect to nonadrenergic non-cholinergic (NANC) inhibitory motorneuronal activation. Muscle strips showed a similar degree of EFS induced relaxation, and maximal nicotinic receptor or $\left[\mathrm{K}^{+}\right]$stimulated relaxation (both operating through NANC neurones) $)^{17} 18$ was unchanged. A complement of selective neurokinin receptor agonists was used to determine the pharmacological profile of tachykinins in the human LOS. Our findings corroborate those of another study that showed lack of functional NK-1 and NK-3 receptors but a predominant NK-2 receptor mediated contraction in the human LOS. ${ }^{19}$ The history of reflux, oesophagitis, and/or columnar lined oesophagus did not alter the sensitivity or maximal responsiveness of the excitatory response to the NK-2 receptor agonist $\left[\beta-\mathrm{Ala}^{8}\right]$-neurokinin A 4-10, but did evidence a reduction in maximal responsiveness to cholinergic excitation using bethanechol.

Muscular cholinergic responses are believed to occur through muscarinic receptor (M3) stimulation of $\mathrm{G}$ protein coupled phospholipase $C$ in the $\operatorname{LOS}^{20}$ with increased intracellular inositol triphosphate and diacylglycerol leading to increased cytoplasmic calcium and activation of smooth muscle. ${ }^{2021} \mathrm{~A}$ similar second messenger pathway is believed to be used by NK-2 receptors in smooth muscle ${ }^{22}$ but this has not yet been characterised specifically for the LOS. However, NK-2 receptor mediated contractions were not concomitantly reduced (slightly greater, in fact) in the Barrett's group, suggestive of a selective deficit in cholinergic based muscle contraction rather than a diminished shared second messenger pathway. This occurred in the area of the LOS most reactive to muscarinic activation - the LOS gastric sling fibres that course over the angle of His. ${ }^{1123} \mathrm{We}$ can speculate that LOS hypotonia observed in the Barrett's patients may be due to a peripheral cholinergic motor deficiency where mean basal LOS pressures are lower than in normal subjects or in patients with oesophagitis alone. ${ }^{2}$ The extent to which cholinergic mechanisms contribute to basal LOS pressure in humans is reported to be $50-80 \%^{24}{ }^{25}$; this is the extent to which atropine lowers resting LOS pressure when administered to healthy subjects. However, this contribution is also similar in patients with gastro-oesophageal reflux disease where atropine reduced basal LOS pressure by $60 \%{ }^{26}$ The component of cholinergic tone in basal LOS pressures in 
reflux affected Barrett's oesophagus has not been determined.

Relaxation in response to isoprenaline in the Barrett's group was greater than that of the SCC group but this did not achieve significance, indicating that $\beta_{2}$ adrenoceptor mediated relaxation of the LOS was unaffected by reflux affected columnar lined mucosa in the oesophagus. The human LOS contains both $\beta_{1}$ and $\beta_{2}$ adrenoceptors; activation of either or both causes LOS relaxation ${ }^{27}$ by direct activation of LOS muscle. This indicates that the capacity for direct LOS smooth muscle relaxation is unperturbed in reflux associated Barrett's oesophagus, at least for $\beta$ adrenergic influences.

The absence of an LOS response to capsaicin administration indicates that either sensory afferent-collateral reflexes are not evident within the sling region of the human LOS or that they are insensitive to capsaicin. The clasp region of the LOS was not studied, so potential activation of capsaicin sensitive pathways has not yet been excluded in this region of the human gastro-oesophageal junction. These pathways, which in the ferret LOS activate inhibitory motorneurones via endogenous substance $P$ release from sensory axon collaterals, ${ }^{28}$ are enhanced in experimental oesophagitis. ${ }^{9}$ In contrast, exogenous substance $\mathrm{P}$ elicited modest excitation of LOS smooth muscle from both SCC and reflux affected Barrett's LOS, which is likely to be due to NK-2 receptor activation in humans. ${ }^{19}$ There was no distinction between responses in either group.

While NANC inhibitory neural activation elicited similar degrees of relaxation in SCC and reflux associated Barrett's LOS, the SCC LOS displayed greater inhibition of relaxation following maximal NANC neuronal stimulation in the presence of tetrodotoxin. This was evident from inhibitory motorneuronal activation using DMPP or $\mathrm{KCl}$ administration. Analysis of individual responses in the reflux associated Barrett's group revealed a disparity in the efficacy of tetrodotoxin - some showed effective blockade of $\mathrm{KCl}$ and DMPP evoked relaxations and some showed little effect (data not shown). Therefore, there may be a subset of reflux affected Barrett's patients who display resistance to axonal sodium channel blockade in the LOS. Tetrodotoxin resistant sodium channels occur in sensory, small diameter dorsal root ganglion neurones ${ }^{29}$ and are upregulated in inflammatory states, ${ }^{30}$ but their expression in enteric motorneurones has not been demonstrated and the physiological implications of their expression in Barrett's oesophagus are not known.

It was not possible to determine if the altered responses of the LOS in Barrett's patients were due to a process of inflammation in the region or associated with intestinal metaplasia in some way. The extent of active ongoing oesophagitis in the Barrett's subjects presenting for oesophagectomy was not determined and therefore a correlation between neuromuscular function and inflammatory states in these biopsies could not be undertaken. However, samples of distal oesophageal mucosae from Barrett's patients show high levels of inflammatory mediators such as leukotrienes, ${ }^{31}$ suggestive of prevailing oesophagitis in this group.

In conclusion, LOS muscle strips from patients with severe reflux disease associated with Barrett's oesophagus exhibit selective reductions in cholinergic based muscle contraction while retaining similar features of basal tone, tachykininergic contractile, and inhibitory muscle and neural function. However, enteric neurones in LOS muscle strips from a subset of reflux affected patients with Barrett's oesophagus displayed resistance to sodium channel blockade, which was revealed at more intense measures of neuronal stimulation. NK-2 receptors are the predominant tachykinin receptor in the human LOS; no evidence for capsaicin sensitive axon collateral reflexes or NK-1 or NK-3 receptors was demonstrated. The attenuated cholinergic LOS muscle contraction may contribute to deficiencies in basal LOS pressures observed clinically in Barrett's oesophagus.

We acknowledge the financial support of Astra Hässle AB. Many thanks to the members of the Professorial and Oesophagogastric Surgical Unit of the Royal Adelaide Hospital, including Glynn Jamieson, Peter Devitt, and Jenny Myers, for facilitating Glynn Jamieson, Peter Devitt, and Jenny Myers, for facilitating
biopsy collection. We thank Dr Charles Malbert for developbiopsy collection. We thank Dr Charles Malbert for develop-
ment of software for computer acquisition and analysis of data (MAD)

1 Riddell RH. Early detection of neoplasia of the esophagus and gastroesophageal junction. $A m$ f Gastroenterol 1996;91:853-63.

2 Lidums I, Holloway R. Motility abnormalities in the columnar-lined esophagus. Gastroenterol Clin N Am 1997; 26:519-31.

3 Niemantsverdriet EC, Timmer R, Breumelhof R, et al. The roles of excessive gastro-esophageal reflux, disordered oesophageal motility and decreased mucosal sensitivity in the pathogenesis of Barrett's oesophagus. Eur $\mathcal{F}$ Gastroenterol Hepatol 1997; 9:515-19.

4 Rakic S, Stein HJ, DeMeester TR, et al. Role of esophageal body function in gastroesophageal reflux disease-
implications for surgical management. $\mathcal{F}$ Am Coll Surg 1997; 185:380-7.

5 Stein HJ, Hoeft SH, DeMeester TR. Functional foregut abnormalities in Barrett's oesophagus. F Thorac Cardiovasc Surg 1993;105:107-11

6 Trimble KC, Pryde A, Heading RC. Lowered oesophageal sensory thresholds in patients with symptomatic but not excess gastro-esophageal reflux: evidence for a spectrum of visceral sensitivity in GORD. Gut 1995;37:7-12.

7 Goldstein SR, Yang G-Y, Curtis SK, et al. Development of esophageal metaplasia and adenocarcinoma in a rat surgical model without the use of a carcinogen. Carcinogenesis 1997;18:2265-70.

8 Li H, Walsh TN, O' Dowd G, et al. Mechanisms of columnar metaplasia and squamous regeneration in experimental Barrett's esophagus. Surgery 1994;115:176-81.

9 Smid SD, Page AJ, O'Donnell T, et al. Oesophagitisinduced changes in capsaicin-sensitive tachykininergic pathways in the ferret lower oesophageal sphincter. Neurogastroenterol Motil 1998;10:403-11.

10 Biancani P, Billett G, Hillemeier C, et al. Acute experimental esophagitis impairs signal transduction in cat lower esophageal sphincter circular muscle. Gastroenterology 1992;103:1199-206.

11 Prieksaitis HG, Diamant NE. Regional differences in cholinergic activity of muscle fibres from the human gastroesophageal junction. Am f Physiol 1997;272:G1321-7

12 Liebermann-Meffert D, Allgower M, Schmid P, et al. Muscular equivalent of the lower esophageal sphincter. Gastroenterology 1979;76:31-8.

13 Stein HJ, Liebermann-Meffert D, DeMeester TM, et al. Three-dimensional pressure image and muscular structure of the human lower esophageal sphincter. Surgery 1995; 117:692-8.

14 Tottrup A, Forman A, Uldbjerg N, et al. Mechanical properties of isolated human esophageal smooth muscle. Am F Physiol 1990;258(3 Pt 1):G338-43.

15 Beveridge AA, Taylor GS. Evidence for a lower oesophageal sphincter in the guinea-pig. Comp Biochem Physiol 1989; 93C:293-301.

16 Allescher HD, Berezin I, Jury J, et al. Characteristics of canine lower esophageal sphincter: a new electrophysological tool. Am f Physiol 1988;255(4 Pt 1):G441-53. 
17 Kortezova N, Velkova V, Mizhorkova Z, et al. Participation of nitric oxide in the nicotine-induced relaxation of the cat lower oesophageal sphincter. F Auton Nerv Syst 1994;50 $73-8$.

18 Tottrup A, Ny L, Alm P, et al. The role of the L-arginine/nitric oxide pathway for relaxation of the human lower oesophageal sphincter. Acta Physiol Scand 1993;149: $451-9$.

19 Huber O, Bertrand C, Bunnett NW, et al. Tachykinins mediate contraction of the human lower esophageal sphincter in vitro via activation of NK-2 receptors. Eur $\mathcal{F}$ Pharmacol 1993;239:103-9.

20 Sohn UD, Harnett KM, Cao W, et al. Acute experimental oesophagitis activates a second signal transduction pathway in cat smooth muscle from the lower oesophageal sphincter. F Pharm Exp Ther 1997;283:1293-304.

21 Biancani P, Harnett KM, Sohn UD, et al. Differential signal transduction pathways in cat lower esophageal sphincter
tone and response to ACh. Am $\mathcal{F}$ Physiol 1994;266(5 Pt 1): G767-74.

22 Guard S, Watson SP. Tachykinin receptor types: classification and membrane signalling mechanisms. Neurochem Int 1991;18:149-65.

23 Preiksaitis HG, Tremblay L, Diamant NE. Cholinergic responses in the cat lower esophageal sphincter show regional variation. Gastroenterology 1994;106:381-8.

24 Dodds W, Dent J, Hogan W, et al. Effect of atropine on the gastroesophageal sphincter. Am f Physiol 1981;240:G290-6.
25 Richardson BJ, Welch RW. Differential effect of atropine on rightward and leftward lower oesophageal sphincter pressure. Gastroenterology 1981;81:85-9.

26 Lidums I, Checklin H, Mittal RK, et al. Effect of atropine on gastro-oesophageal reflux and transient lower oesophageal relaxations in patients with gastro-oesophageal reflux disease. Gut 1998;43:12-16.

27 Tottrup A, Forman A, Madsen G, et al. The actions of some beta-receptor agonists and xanthines on isolated muscle strips of the human lower oesophageal sphincter. Pharmacol Toxicol 1990;67:340-3.

28 Smid SD, Lynn PA, Templeman R, et al. Activation of nonadrenergic non-cholinergic inhibitory pathways by endogenous and exogenous tachykinins in the ferret lower oesophageal sphincter. Neurogastroenterol Motil 1998;10: 149-56.

29 Akopian AN, Sivilotti L, Wood JN. A tetrodotoxin-resistant voltage-gated sodium channel expressed by sensory neurons. Nature 1996;379:257-62.

30 Tanaka M, Cummins TR, Ishikawa K, et al. SNS Na+ channel expression increases in dorsal root ganglion neurons in the carrageenan inflammatory pain model. Neuroreport 1998;9:967-72.

31 Triadafilopoulos G, Kaczynska M, Iwane M. Esophageal mucosal eicosanoids in gastroesophageal reflux disease and Barrett's esophagus. Am f Gastroenterol 1996;91:65-74. 